\title{
Concentration of meropenem in patients with sepsis and acute kidney injury before and after initiation of continuous renal replacement therapy: a prospective observational trial
}

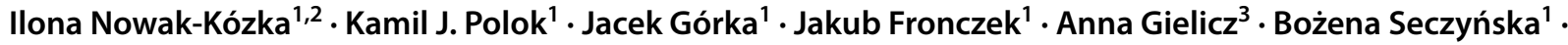 \\ Mirosław Czuczwar ${ }^{4}$ Bartosz Kudliński ${ }^{5}$ - Wojciech Szczeklik ${ }^{1}$
}

Received: 21 August 2019 / Revised: 13 November 2019 / Accepted: 17 December 2019 / Published online: 4 January 2020

(c) The Author(s) 2020

\begin{abstract}
Background The effect of renal replacement therapy on drug concentrations in patients with sepsis has not been fully elucidated because the pharmacokinetic properties of many antimicrobials are influenced by both pathophysiological and treatment-related factors. The aim of this study was to determine meropenem concentrations in patients with sepsis before and after the initiation of continuous venovenous hemodialysis with regional citrate anticoagulation (RCA-CVVHD).

Methods The study included 15 critically ill patients undergoing RCA-CVVHD due to sepsis-induced acute kidney injury. All participants received $2 \mathrm{~g}$ of meropenem every $8 \mathrm{~h}$ in a prolonged infusion lasting $3 \mathrm{~h}$. Meropenem concentrations were measured in blood plasma using high-performance liquid chromatography coupled with tandem mass spectrometry. Blood samples were obtained at six-time points prior to and at six-time points after introducing RCA-CVVHD.

Results The median APACHE IV and SOFA scores on admission were 118 points (interquartile range [IQR] 97-134 points) and 19.5 points (IQR 18-21 points), respectively. There were no significant differences in the plasma concentrations of meropenem measured directly before RCA-CVVHD and during the first $450 \mathrm{~min}$ of the procedure. The drug concentration reached its peak $2 \mathrm{~h}$ after initiating the infusion and then steadily declined.

Conclusions The concentration of high-dose meropenem $(2 \mathrm{~g}$ every $8 \mathrm{~h})$ administered in a prolonged infusion was similar before and after the introduction of RCA-CVVHD in patients with sepsis who developed acute kidney injury.
\end{abstract}

Keywords Continuous venovenous hemodialysis $\cdot$ Meropenem $\cdot$ Regional citrate anticoagulation $\cdot$ Sepsis $\cdot$ Therapeutic drug monitoring

Electronic supplementary material The online version of this article (https://doi.org/10.1007/s43440-019-00056-3) contains supplementary material, which is available to authorized users.

Wojciech Szczeklik

wojciech.szczeklik@uj.edu.pl

1 Department of Intensive Care and Perioperative Medicine, Jagiellonian University Medical College, ul. Skawińska 8, 31-066 Kraków, Poland

2 Human Nutrition Department, Institute of Public Health, Faculty of Health Sciences, Jagiellonian University Medical College, ul. Grzegórzecka 20, 31-531 Kraków, Poland

\section{Introduction}

Optimal antibiotic dosing is crucial in the therapeutic process, especially in critically ill patients with sepsis. These patients are at a significantly higher risk of antibiotic underdosing due to pathophysiological changes associated with large fluid shifts, resulting in an increased volume of distribution, alterations in both renal and liver clearance, as well as decreased

3 Department of Internal Medicine, Jagiellonian University Medical College, ul. Skawińska 8, 31-066 Kraków, Poland

4 2nd Department of Anesthesiology and Intensive Care, Medical University of Lublin, ul. Staszica 16, 20-081 Lublin, Poland

5 Department of Teaching Anaesthesiology and Intensive Therapy, Poznan University of Medical Sciences, ul. Fredry 10, 61-701 Poznań, Poland 
concentrations of plasma proteins [1, 2]. Acute kidney injury (AKI) is a common life-threatening complication of sepsis, which often requires an introduction of continuous renal replacement therapy (CRRT).

Meropenem displays time-dependent antibacterial activity, that is, its efficacy is associated with the percentage of time in which the free drug concentration exceeds the minimum inhibitory concentration (MIC), referred to as $\% \mathrm{fT}_{>\mathrm{MIC}}$ [3]. The drug has been shown to exert bacteriostatic effects at an $\mathrm{fT}_{>\mathrm{MIC}}$ of $20 \%$ and bactericidal effects at an $\mathrm{fT}_{>\mathrm{MIC}}$ of $40 \%$ [4]. However, the latest evidence on patients with sepsis undergoing CRRT suggests that clinicians should aim at an $\mathrm{fT}_{>\mathrm{MIC}}$ of $100 \%$ [5]. Antibacterial activity of meropenem may be maximal when the antibiotic concentration exceeds the MIC for the specific type of bacteria four- to five-fold for the entire duration of the dosing interval [6].

The degree of antibiotic clearance varies depending on the physicochemical and pharmacokinetic properties of the drug [7]. Hydrophilic antibiotics, including carbapenems, have a small volume of distribution, low molecular weight, and are bound to proteins to a minimal degree, which facilitates their rapid elimination during CRRT [8, 9]. However, their pharmacokinetic properties are known to be influenced by extracorporeal blood purification procedures, including CRRT. Moreover, an additional use of anticoagulation required for CRRT may cause unpredictable drug interactions [10]. Drug concentrations may also vary depending on the type of solute removal during CRRT (e.g., diffusion, convection), properties of the semipermeable membrane of the filter, the rate of ultrafiltration, as well as the dose of dialysis. Finally, drug clearance is also influenced by CRRT settings and the patient's demographic and clinical characteristics, including age, urine output, and countercurrent dialysate flow rates [11].

Several authors have suggested that drug doses should be carefully adjusted based on its blood concentration [12]. Continuous renal replacement therapy with regional citrate anticoagulation (RCA-CRRT) is becoming increasingly widely used in the management of critically ill patients with AKI [13]. However, there are no evidence-based recommendations on the dosing of drugs commonly used in patients with severe sepsis and septic shock treated with RCA-CRRT. Therefore, we aimed to assess whether there are significant differences in the plasma concentrations of meropenem administered in a prolonged infusion before and during RCA-CRRT among patients with sepsis who developed AKI.

\section{Materials and methods}

\section{Patients}

This prospective observational cohort study was conducted in the Intensive Care Unit (ICU) at University Hospital in
Krakow, Poland, between January 2014 and January 2017. All procedures involving human participants were conducted in accordance with the ethical standards of the institutional and national research committees as well as with the 1964 Helsinki Declaration and its later amendments or comparable ethical standards. The study was approved by the Bioethics Committee of Jagiellonian University (ul. Grzegórzecka 20, Kraków; protocol number, KBET/262/B/2013; date of approval, 27 January 2014).

This report conforms to the STROBE guidelines; the checklist with specific pages where each requirement was addressed can be found in Supplementary Table 1.

The inclusion criteria were as follows: (1) age older than 35 years and younger than 85 years; (2) diagnosis of severe sepsis or septic shock (according to the criteria of the Surviving Sepsis Campaign Consensus) [14]; (3) clinical indications for CRRT due to AKI, determined in accordance with the criteria adopted by Kidney Disease Improving Global Outcomes (KDIGO) recommendations: hyperkalemia (serum potassium concentration $>6.5 \mathrm{mmol} / \mathrm{L}$ or rapidly rising), refractory fluid overload, metabolic acidosis, and signs of uremia (such as pericarditis or encephalopathy) [15]; (4) use of regional citrate anticoagulation (RCA) during CRRT; and (5) treatment with high doses of meropenem ( 2 g every $8 \mathrm{~h}$ ) in prolonged infusions (lasting $3 \mathrm{~h}$ ).

The exclusion criteria were lack of patient consent, pregnancy, bilirubin concentrations exceeding $150 \mu \mathrm{mol} / \mathrm{L}$, blood transfusion of more than $50 \%$ of the circulating volume in the past $8 \mathrm{~h}$, and the use of other extracorporeal techniques (such as plasmapheresis) in the past $24 \mathrm{~h}$.

\section{Methods}

Patients' medical records were analyzed and relatives were interviewed to obtain demographic and clinical data such as age, sex, weight, height, comorbidities, site of infection, and laboratory parameters at baseline and during CRRT (i.e., complete blood count, coagulation parameters, serum concentrations of creatinine, urea, bilirubin, albumin, total protein, levels of inflammatory biomarkers including $\mathrm{C}$-reactive protein, and procalcitonin).

The severity of clinical condition was assessed with the Acute Physiology and Chronic Health Evaluation (APACHE) IV score on admission and the Sequential Organ Failure Assessment (SOFA) score on the 1st, 3rd, and 7th day of ICU stay.

\section{Continuous renal replacement therapy}

Continuous renal replacement therapy was initiated according to the local practice and study protocol. Continuous venovenous hemodialysis with RCA (RCA-CVVHD) was used. The main indications for CRRT were metabolic 
acidosis, oliguria with fluid overload, and hyperkalemia. For CRRT, commercially available equipment and solutions were used: MultiFiltrate ${ }^{\circledR}$ with the integrated $\mathrm{Ci}-\mathrm{Ca}^{\circledR}$ system, 1.8- $\mathrm{m}^{2}$ capillary hemofilters Ultraflux ${ }^{\circledR}$ AV $1000 \mathrm{~S}$ with membrane Fresenius Polysulfone ${ }^{\circledR}$, Dialysate K2 or K4 (Fresenius Medical Care, Bad Hamburg, Germany). Anticoagulation was performed using $4 \%$ trisodium citrate (citrate flow rates were subsequently adjusted based on postfilter ionized calcium levels) and calcium chloride solution $\left(\mathrm{CaCl}_{2}\right.$ flow rates were based on calcium levels measured in arterial blood).

All CRRT settings (timing, modality, intensity of dialysis, RCA) were identical for each participant at the beginning of the procedure and were subsequently adapted to the patient's clinical status in accordance with KDIGO recommendations (blood flow 120-150 mL/min; dialysate flow rate $2000-3450 \mathrm{~mL} / \mathrm{h}$; patient fluid removal [ultrafiltration], 0 in the first hour, and then $100 \mathrm{~mL} / \mathrm{h}$ and higher according to clinical condition) [11]. The CRRT intensity was calculated as an effluent flow rate (dialysate rate $[\mathrm{mL} / \mathrm{h}]+$ ultrafiltrate $[\mathrm{mL} / \mathrm{h}] /$ weight $[\mathrm{kg}]$ ). Regarding the CRRT settings, the median intensity at baseline was $31.4 \mathrm{~mL} / \mathrm{kg} / \mathrm{h}$ (range $25-35 \mathrm{~mL} / \mathrm{kg} / \mathrm{h}$ ), and the median blood flow was $124 \mathrm{~mL} /$ min (range $120-150 \mathrm{~mL} / \mathrm{min}$ ). All CRRT settings, including dialysate rate, ultrafiltrate rate, blood flow, as well as $\mathrm{CaCl}_{2}$ and citrate solution flow rates, were recorded for each participant.

\section{Meropenem dosing}

Meropenem was administered intravenously through a separate lumen of a central venous catheter in a prolonged infusion, according to the dosing schedule identical for all patients ( $2 \mathrm{~g}$ in 3 -h infusion administered every $8 \mathrm{~h}$ ). Each dose was reconstituted in $50 \mathrm{~mL}$ of $0.9 \%$ sodium chloride.

\section{Blood sampling}

Blood samples for each patient were collected at specified time points before the drug administration and then at 30,60 , $90,120,180$, and $450 \mathrm{~min}$ after meropenem infusion. The first set of samples was collected around the time of the first meropenem infusion after the decision on the introduction of RCA-CVVHD was made based on the above criteria for patients with sepsis. Subsequently, on the same day, RCACVVHD was initiated according to local practice by the ICU personnel. The second set of samples was collected when the first meropenem infusion was given during RCA-CRRT. For each sample, $2 \mathrm{~mL}$ of blood was collected from an arterial catheter. Samples were centrifuged at $3500 \mathrm{rpm}$ for $10 \mathrm{~min}$ at $4{ }^{\circ} \mathrm{C}$ and stored at $-80{ }^{\circ} \mathrm{C}$ until further analysis.

The study timeline is shown in Fig. 1.

\section{Meropenem measurements}

The measurement of plasma meropenem concentrations was performed in the Department of Molecular Biology and Clinical Genetics of Jagiellonian University Medical College. The concentrations of unbound drug were measured using high-performance liquid chromatography (Prominence, Shimadzu, Tokyo, Japan) coupled with tandem mass spectrometry (Qtrap 4000, AB Sciex, Toronto, Canada). The tris buffer $(0.2 \mathrm{~mL})$ and chemically identical deuterated internal standard meropenem-d6 $(5 \mu \mathrm{g})$ were added to plasma $(0.2 \mathrm{~mL})$. The sample was extracted with the mixture of tert-butyl methyl ether and methanol (4:1, $\mathrm{v}: \mathrm{v})$ twice. An organic layer was collected and evaporated under the stream of nitrogen. After evaporating the solvent, the residue was reconstituted in mobile phase $(30 \mu \mathrm{l})$. Chromatography separation was performed using Zorbax Eclipse XDB C- 18 column $(1 \times 50 \mathrm{~mm}, 3 \mu \mathrm{m})$ (Agilent, Santa Clara, CA, USA) and mobile phases consisting of water-formic acid (100:0.1\%) and acetonitrile-methanol-formic acid (50:50:0.1\%) to gradient elution. Meropenem was measured using the multiple reaction monitoring in the positive ionization mode, monitoring transition $\mathrm{m} / \mathrm{z} 384>141$ and $\mathrm{m} / \mathrm{z}$ $384>68$ for meropenem and $\mathrm{m} / \mathrm{z} 390>147$ and $\mathrm{m} / \mathrm{z} 390>68$ for deuterated meropenem-d6. Meropenem concentrations were determined using a calibration curve in the range of $0.05-250 \mu \mathrm{g} / \mathrm{mL}\left(r^{2}=0.997\right)[16,17]$.

\section{Statistical analysis}

Dependent quantitative variables were compared using the paired Student $t$ test or the Wilcoxon test for matched pairs depending on the distribution of the difference between two variables. Observed correlations were analyzed using a linear mixed model. Confidence intervals and $p$ values were calculated using the likelihood ratio method. The normality assumption was examined using the Shapiro-Wilk test.

The level of 0.05 was assumed as significant. The analysis was carried out using the R software, version 3.4.1. (R Foundation for Statistical Computing, Vienna, Austria).

\section{Results}

The study included 15 eligible patients (mean age, $57.8 \pm 7.5$ years; five women, ten men) with sepsis or septic shock who received meropenem and RCA-CVVHD. Baseline demographic and clinical characteristics of the patients are shown in Table 1.

All patients were mechanically ventilated due to respiratory failure, and 13 patients (87\%) required vasopressors. The median APACHE IV and SOFA scores were 118 points (interquartile range [IQR] $97-134$ points) and 19.5 points 
Fig. 1 Flow chart of the study timeline showing the time of meropenem administration and use of continuous venovenous hemodialysis with regional citrate anticoagulation (RCACVVHD). ${ }^{\dagger}$ End of infusion. Dotted area represents the time of meropenem infusion

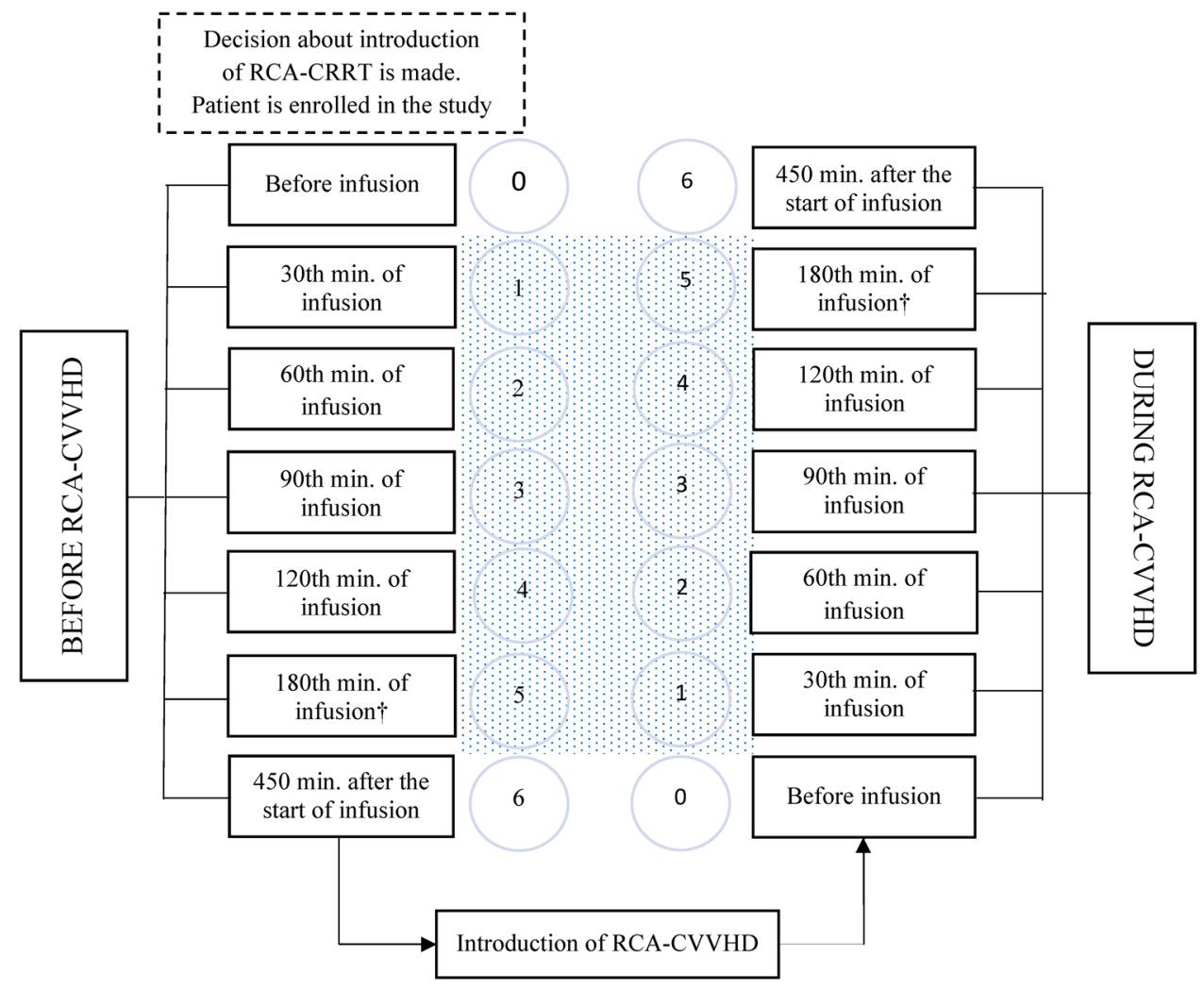

(IQR 18-21 points), respectively. The mean predicted mortality rate for the APACHE IV and SOFA scores was $68.6 \%$ and $>90 \%$, respectively.

Respiratory tract infection was the most common cause of sepsis $(73 \% ; 11$ patients), followed by urinary tract infection (27\%; four patients). Bloodstream infection was confirmed in four cases (27\%; four patients). The pathogen for sepsis was identified in 13 cases (87\%): Gram-positive bacteria in five cases (Staphylococcus aureus, vancomycin-resistant enterococci, coagulase-negative staphylococci) and Gramnegative bacteria in 8 cases (Acinetobacter baumannii, Pseudomonas aeruginosa, Klebsiella pneumoniae, Citrobacter freundii, and Escherichia coli). Data concerning infection sites and pathogens are shown in Table 2.

\section{Analysis of meropenem concentrations}

We did not find significant differences in meropenem concentrations measured before and during CRRT at any time point after drug infusion (Table 3 ). The drug concentration in plasma reached its peak $2 \mathrm{~h}$ after the start of the infusion and then steadily declined, as shown in Fig. 2. Moreover, there were no statistically significant differences in meropenem concentrations measured before and during CRRT at any time point after drug infusion among patients with anuria $(66.7 \%$; ten patients) and those with residual diuresis (33.3\%; 5/patients). Among the five patients with available
MIC for meropenem, the concentrations were $0.25 \mu \mathrm{g} / \mathrm{mL}$ or less in four cases $(66.7 \%)$ and $0.125 \mu \mathrm{g} / \mathrm{mL}$ in two cases (33.3\%). The number of measurements in which plasma meropenem concentrations exceeded the respective hypothetical MICs before and during RCA-CRRT is shown in Table 4.

\section{Discussion}

In this prospective observational study including 15 patients with sepsis-induced AKI, we found that prolonged infusions of meropenem resulted in similar concentrations of the drug before and after the initiation of CRRT.

Critically ill patients presenting with severe sepsis or septic shock are at higher risk of receiving insufficient doses of antimicrobials due to increased volume of distribution, hypoalbuminemia, as well as altered renal and nonrenal clearance [8]. To improve outcomes in this challenging population, it is crucial to achieve proper antibiotic concentrations. Several authors have suggested that the antibiotic concentration should be systematically measured in these patients and titrated accordingly [18]. It is particularly complicated in the context of severe sepsis or septic shock with concomitant AKI requiring CRRT. In a study by Economou et al. [19], the antibiotic dose had to be adjusted in $35 \%$ of critically ill patients undergoing CRRT in whom therapeutic 
Table 1 Baseline demographic and clinical characteristics of the study group
Table 2 Infection events in the study group

\begin{tabular}{ll}
\hline Site of infection & Value \\
\hline Respiratory tract; $n(\% ; 95 \% \mathrm{CI})$ & $11(73.3 \% ; 44.8-91.1 \%)$ \\
Urinary tract; $n(\% ; 95 \% \mathrm{CI})$ & $4(27 \% ; 8.9-55.2 \%)$ \\
Bloodstream $n(\% ; 95 \% \mathrm{CI})$ & $4(27 \% ; 8.9-55.2 \%)$ \\
Pathogen identified; $n$ & \\
Acinetobacter baumanii & 2 \\
Coagulase-negative staphylococci & 2 \\
Staphylococcus aureus & 2 \\
Klebsiella pneumoniae & 2 \\
Pseudomonas aeruginosa & 2 \\
Citrobacter freundii & 1 \\
Escherichia coli & 1 \\
Vancomycin-resistant enterococci & 1 \\
\hline
\end{tabular}

\begin{tabular}{|c|c|}
\hline Characteristic & Value \\
\hline Age (years); mean (SD) & $57.8(7.5)$ \\
\hline Male sex; $n(\% ; 95 \% \mathrm{CI})$ & $10(66.7 \% ; 38.7-87.0 \%)$ \\
\hline Body weight $(\mathrm{kg})$; mean (SD) & $81(8.6)$ \\
\hline BMI $\left(\mathrm{kg} / \mathrm{m}^{2}\right)$; mean $(\mathrm{SD})$ & $27.5(3.2)$ \\
\hline APACHE IV score; median (IQR) & $118(97-134)$ \\
\hline Day 1 SOFA score; median (IQR) & $19.5(18-21)$ \\
\hline Day 3 SOFA score (12/15 patients); median (IQR) & $20.5(17-23)$ \\
\hline Day 7 SOFA score (10/15 patients); median (IQR) & $18.5(16.3-21)$ \\
\hline \multicolumn{2}{|l|}{ Organ dysfunction, $n(\% ; 95 \% \mathrm{CI})$} \\
\hline Respiratory (ARDS) & $15(100 \% ; 74.7-100 \%)$ \\
\hline Renal & $15(100 \% ; 74.7-100 \%)$ \\
\hline Cardiovascular & $11(73.3 \% ; 44.8-91.1 \%)$ \\
\hline Hematologic & $10(66.7 \% ; 38.7-87.0 \%)$ \\
\hline Central nervous system & $2(13.3 \% ; 2.3-41.6 \%)$ \\
\hline Liver & $2(13.3 \% ; 2.3-41.6 \%)$ \\
\hline \multicolumn{2}{|l|}{ Medication, $n(\%$; 95\% CI $)$} \\
\hline Vasopressors & $13(86.7 \% ; 58.4-97.7 \%)$ \\
\hline Mechanical ventilation & $15(100 \% ; 74.7-100 \%)$ \\
\hline \multicolumn{2}{|l|}{ Laboratory results } \\
\hline White blood cell $\left(\times 10^{9} / \mathrm{L}\right)$; mean $(\mathrm{SD})$ & $10.9(4.2)$ \\
\hline Serum albumin $(\mathrm{g} / \mathrm{dL})$; mean $(\mathrm{SD})$ & $25.5(3.1)$ \\
\hline Baseline serum creatinine $(\mu \mathrm{mol} / \mathrm{L}) ;$ mean $(\mathrm{SD})$ & $138.5(41.3)$ \\
\hline Pre-CRRT serum creatinine ( $\mu \mathrm{mol} / \mathrm{L})$; mean $(\mathrm{SD})$ & $235.7(52.1)$ \\
\hline Preserved diuresis; $n(\% ; 95 \% \mathrm{CI})$ & $5(33.3 \% ; 9.5-57.2 \%)$ \\
\hline Volume of diuresis (mL/24 h); median (IQR) & $162.5(300-900)$ \\
\hline ICU survivors; $n(\% ; 95 \% \mathrm{CI})$ & $8(53.3 \% ; 27.4-77.7 \%)$ \\
\hline \multicolumn{2}{|l|}{ CRRT settings } \\
\hline Blood flow rate (mL/min); mean (SD) & $124(5.8)$ \\
\hline Dialysate flow rate (mL/h); median (IQR) & $2400(2000-2700)$ \\
\hline Ultrafiltrate (mL/h); median (IQR) & $100(50-100)$ \\
\hline
\end{tabular}

APACHE IV Acute Physiology and Chronic Health Evaluation IV, ARDS acute respiratory distress syndrome, $B M I$ body mass index, SOFA sequential organ failure assessment drug monitoring (TDM) was performed [19]. Unfortunately, TDM is rarely available in ICUs worldwide; thus, the appropriateness of antibiotic dosing usually remains uncertain.

Previous studies evaluating meropenem concentrations during CRRT, based on pharmacokinetic models and simulations, have reported conflicting results [20, 21]. Moreover, these discrepancies were related not only to dosing but also to the administration method (continuous infusion versus intermittent bolus administration; 30 min versus $3 \mathrm{~h}$ ) [22, 23]. The recommended dose for such patients ranges from $500 \mathrm{mg}$ every $12 \mathrm{~h}$ to $2 \mathrm{~g}$ every $8 \mathrm{~h}$. In this study, we decided to use the latter dose due to the high prevalence of multidrug-resistant bacteria, high ultrafiltration and dialysate flow rates, as well as the presence of the abovementioned factors inherent in patients with sepsis that reduce plasma concentrations of the antibiotic [24]. Another difficulty is associated with the largely unpredictable influence of various 
Table 3 Meropenem concentrations $(\mu \mathrm{g} / \mathrm{mL})$ in blood before and during continuous renal replacement therapy

\begin{tabular}{lllllllll}
\hline Time point & CRRT & $N$ & Median & Min & Max & $Q 1$ & $Q 3$ & $p$ value* \\
\hline (0) & Before & 15 & 8.8 & 0.1 & 38.7 & 3.15 & 17.05 & 0.359 \\
& During & 15 & 11.9 & 2.7 & 32.4 & 6.65 & 20.65 & \\
(1) $30 \mathrm{~min}$ & Before & 15 & 15 & 4.3 & 48.6 & 7.35 & 25.2 & 0.169 \\
& During & 15 & 19.4 & 6.2 & 48.4 & 16.2 & 21.85 & \\
(2) $60 \mathrm{~min}$ & Before & 15 & 18.2 & 5.3 & 53 & 12.25 & 29.6 & 0.151 \\
& During & 15 & 24.4 & 9.3 & 46.8 & 19.25 & 37 & \\
(3) $90 \mathrm{~min}$ & Before & 15 & 23.2 & 13.2 & 49.3 & 16.45 & 32.2 & 0.389 \\
& During & 15 & 27.1 & 11.1 & 43.1 & 24.35 & 34.4 & \\
(4) $120 \mathrm{~min}$ & Before & 15 & 23.7 & 15.1 & 62 & 19.95 & 36.7 & 0.804 \\
& During & 15 & 31.1 & 12.2 & 41.5 & 20.2 & 36.15 & \\
(5) $180 \mathrm{~min}$ & Before & 15 & 24.9 & 2 & 60.6 & 18.7 & 35.65 & 0.847 \\
& During & 15 & 27.6 & 10.7 & 52.4 & 18.1 & 34.4 & \\
(6) $450 \mathrm{~min}$ & Before & 15 & 15.4 & 2.9 & 52.4 & 7.28 & 22.85 & 0.064 \\
& During & 14 & 10.9 & 1.8 & 30.6 & 7.75 & 14.8 & \\
\hline
\end{tabular}

Continuous variables are expressed as median and interquartile range $(Q 1,25$ th percentile and $Q 3,75$ th percentile)

$C R R T$ continuous renal replacement therapy

*Significant $p$ value $(<0.05)$; paired Student $t$ test or the Wilcoxon test for matched pairs depending on the distribution of the difference between two variables

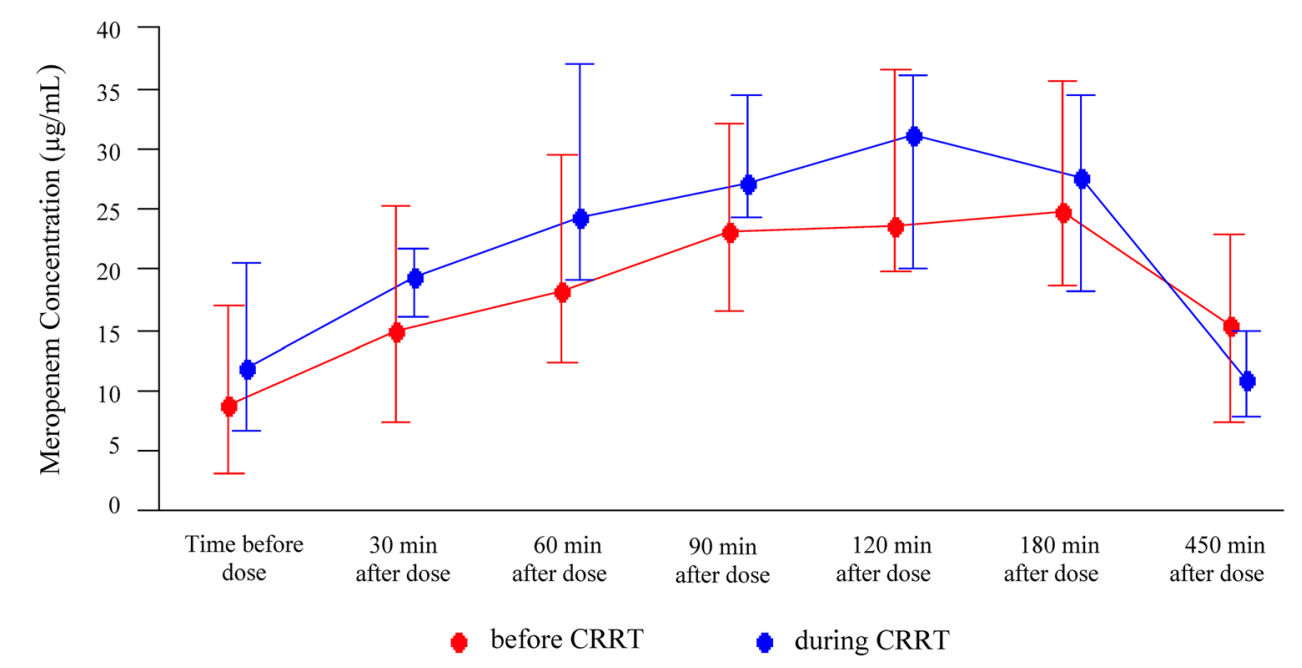

Fig. 2 Meropenem concentration before and during continuous renal replacement therapy (CRRT). Dots and whiskers represent median and interquartile range, respectively modalities of CRRT on antibiotic concentrations. Some studies have shown that $\beta$-lactam clearance can vary at least partially depending on the CRRT modality [25]. Finally, little is known about the effect of anticoagulation used for CRRT and antibiotic concentrations.

The RCA-CVVHD is gaining popularity in the routine management of critically ill patients [13]. However, the recommendations on dosing of widely used medications among patients with severe sepsis and septic shock treated with RCA-CRRT are lacking. Therefore, we decided to determine the effect of RCA-CVVHD on meropenem concentrations in patients with AKI treated in the ICU due to severe sepsis or septic shock. Our patients had high median APACHE IV and SOFA scores indicating critical condition, thus making them suitable candidates for RCA according to KDIGO recommendations [15]. Initial CRRT intensity was identical for all patients and was consistent with KDIGO recommendations. Moreover, administration of an identical dose of meropenem in all patients as well as fixed dosing before CRRT and in the first hours after its initiation provided a well-suited setting for the assessment of differences in drug concentrations associated with RCA-CVVHD. We did not find any differences between the plasma concentrations of meropenem before RCACVVHD and in the first $450 \mathrm{~min}$ of the procedure. Our results suggest that antibiotic dose adjustment might not be 
Table 4 Achievement of hypothetical minimum inhibitory concentration (MIC) before and during renal replacement therapy with regional citrate anticoagulation (RCA-CRRT) among study participants

\begin{tabular}{|c|c|c|c|c|c|c|c|}
\hline \multirow{2}{*}{$\begin{array}{l}\text { Number of measurements } \\
C_{\text {Meropenem }}>\text { MIC }\end{array}$} & \multicolumn{7}{|c|}{ Hypothetical MIC $(\mu \mathrm{g} / \mathrm{mL})$} \\
\hline & 0.25 & 0.5 & 1 & 2 & 4 & 8 & 16 \\
\hline \multicolumn{8}{|l|}{ Before RCA-CRRT } \\
\hline $0 / 7$ & $15(100 \%)$ & $15(100 \%)$ & $15(100 \%)$ & $15(100 \%)$ & $15(100 \%)$ & $15(100 \%)$ & $15(100 \%)$ \\
\hline $1 / 7$ & $15(100 \%)$ & $15(100 \%)$ & $15(100 \%)$ & $15(100 \%)$ & $15(100 \%)$ & $15(100 \%)$ & $15(100 \%)$ \\
\hline $2 / 7$ & $15(100 \%)$ & $15(100 \%)$ & $15(100 \%)$ & $15(100 \%)$ & $15(100 \%)$ & $15(100 \%)$ & $13(86.7 \%)$ \\
\hline $3 / 7$ & $15(100 \%)$ & $15(100 \%)$ & $15(100 \%)$ & $15(100 \%)$ & $15(100 \%)$ & $15(100 \%)$ & $12(80 \%)$ \\
\hline $4 / 7$ & $15(100 \%)$ & $15(100 \%)$ & $15(100 \%)$ & $15(100 \%)$ & $15(100 \%)$ & $14(93.3 \%)$ & $9(60 \%)$ \\
\hline $5 / 7$ & $15(100 \%)$ & $15(100 \%)$ & $15(100 \%)$ & $15(100 \%)$ & $15(100 \%)$ & $11(73.3 \%)$ & $8(53.3 \%)$ \\
\hline $6 / 7$ & $15(100 \%)$ & $15(100 \%)$ & $15(100 \%)$ & $15(100 \%)$ & $13(86.7 \%)$ & $9(60 \%)$ & $6(40 \%)$ \\
\hline $7 / 7$ & $14(93.3 \%)$ & $13(86.7 \%)$ & $12(80 \%)$ & $11(73.3 \%)$ & $9(60 \%)$ & $7(46.7 \%)$ & $5(33.3 \%)$ \\
\hline \multicolumn{8}{|l|}{ During RCA-CRRT } \\
\hline $0 / 7$ & $15(100 \%)$ & $15(100 \%)$ & $15(100 \%)$ & $15(100 \%)$ & $15(100 \%)$ & $15(100 \%)$ & $15(100 \%)$ \\
\hline $1 / 7$ & $15(100 \%)$ & $15(100 \%)$ & $15(100 \%)$ & $15(100 \%)$ & $15(100 \%)$ & $15(100 \%)$ & $14(93.3 \%)$ \\
\hline $2 / 7$ & $15(100 \%)$ & $15(100 \%)$ & $15(100 \%)$ & $15(100 \%)$ & $15(100 \%)$ & $15(100 \%)$ & $14(93.3 \%)$ \\
\hline $3 / 7$ & $15(100 \%)$ & $15(100 \%)$ & $15(100 \%)$ & $15(100 \%)$ & $15(100 \%)$ & $15(100 \%)$ & $13(86.7 \%)$ \\
\hline $4 / 7$ & $15(100 \%)$ & $15(100 \%)$ & $15(100 \%)$ & $15(100 \%)$ & $15(100 \%)$ & $15(100 \%)$ & $12(80 \%)$ \\
\hline $5 / 7$ & $15(100 \%)$ & $15(100 \%)$ & $15(100 \%)$ & $15(100 \%)$ & $15(100 \%)$ & $14(93.3 \%)$ & $10(66.7 \%)$ \\
\hline $6 / 7$ & $14(93.3 \%)$ & $14(93.3 \%)$ & $14(93.3 \%)$ & $14(93.3 \%)$ & $13(86.7 \%)$ & $10(66.7 \%)$ & $5(33.3 \%)$ \\
\hline $7 / 7$ & $13(86.7 \%)$ & $13(86.7 \%)$ & $13(86.7 \%)$ & $12(80 \%)$ & $11(73.3 \%)$ & $8(53.3 \%)$ & $1(6.7 \%)$ \\
\hline
\end{tabular}

Data presented as number (percentage) of patients

necessary while using RCA-CVVHD, particularly shortly after its initiation, which is contradictory to an observed tendency to reduce doses recommended for CRRT in this period [18]. Our observations also cast doubt on the use of TDM in the first hours after the introduction of RCACVVHD and suggest that high doses of meropenem can be safely administered. To our knowledge, there have been no similar prospective studies evaluating the influence of RCA-CVVHD on meropenem concentrations in patients with severe sepsis or septic shock.

We are aware of several important limitations of our study. First, the study group was relatively small, but at the same time, it was very homogeneous as it consisted of critically ill patients with severe sepsis or septic shock with very high predicted mortality according to commonly used scoring systems for the severity of illness in critical care. Second, we did not measure meropenem concentrations in the time points exceeding the prespecified $450 \mathrm{~min}$. Such a measurement would allow us to evaluate the effect of filter lifespan during the procedure. Also, we did not measure meropenem concentrations in urine, ultrafiltrate, and at the site of infection. The lack of these measurements limited our ability to calculate several significant pharmacokinetic variables. Finally, the study group was heterogenous in terms of residual diuresis, a factor that influences drug clearance.

\section{Conclusion}

Plasma concentrations of high-dose meropenem ( $2 \mathrm{~g}$ every $8 \mathrm{~h}$ ) administered in a prolonged infusion were similar before and after the initiation of RCA-CVVHD.

Acknowledgements The manuscript was edited by a professional English proofreader, Małgorzata Wiesner-Spyrczyńska. The authors thank Maria Foks and Alicja Dudek for help in clinical data extraction and database management.

Author contributions IN-K: conceptualization, methodology, writingoriginal draft preparation, resources. KJP: writing-reviewing and editing, software, validation, formal analysis, data curation. JG: writingreviewing and editing, resources. JF: writing-reviewing and editing, software, validation, formal analysis, data curation. AG: investigation, resources. BS: investigation, resources. MC: writing-reviewing and editing, validation. BK: writing-reviewing and editing, validation. WS: methodology, writing-reviewing and editing, supervision.

Funding This study was supported by a grant awarded to I. NowakKozka by the National Science Centre Poland (Preludium: predoctoral Grants, No. 2014/15/N/NZ5/03646). Open access publishing of this article was funded by the Ministry of Science and Higher Education under the agreement No. 879/P-DUN/2019.

\section{Compliance with ethical standards}

Conflict of interest The authors declare no conflicts of interest. 
Ethics approval and consent to participate The study protocol was approved by the Jagiellonian University Bioethics Committee (No. KBET/262/B/2013).

Consent for publication All authors have reviewed and approved the manuscript for publication.

Open Access This article is licensed under a Creative Commons Attribution 4.0 International License, which permits use, sharing, adaptation, distribution and reproduction in any medium or format, as long as you give appropriate credit to the original author(s) and the source, provide a link to the Creative Commons licence, and indicate if changes were made. The images or other third party material in this article are included in the article's Creative Commons licence, unless indicated otherwise in a credit line to the material. If material is not included in the article's Creative Commons licence and your intended use is not permitted by statutory regulation or exceeds the permitted use, you will need to obtain permission directly from the copyright holder. To view a copy of this licence, visit http://creativecommons.org/licenses/by/4.0/.

\section{References}

1. Rhodes A, Evans LE, Alhazzani W, Levy MM, Antonelli M, Ferrer R, et al. Surviving sepsis campaign: international guidelines for management of sepsis and septic shock: 2016. Intensive Care Med. 2017;43(3):304-77. https://doi.org/10.1007/s0013 4-017-4683-6.

2. Blot SI, Pea F, Lipman J. The effect of pathophysiology on pharmacokinetics in the critically ill patient-concepts appraised by the example of antimicrobial agents. Adv Drug Deliv Rev. 2014;77:3-11. https://doi.org/10.1016/j.addr.2014.07.006.

3. Drusano GL. Antimicrobial pharmacodynamics: critical interactions of 'bug and drug'. Nat Rev Microbiol. 2004;2(4):289-300. https://doi.org/10.1038/nrmicro862.

4. Nicolau DP. Pharmacodynamic optimization of beta-lactams in the patient care setting. Crit Care. 2008;12(Suppl 4):S2. https:// doi.org/10.1186/cc6818.

5. Burger R, Guidi M, Calpini V, Lamoth F, Decosterd L, Robatel C, et al. Effect of renal clearance and continuous renal replacement therapy on appropriateness of recommended meropenem dosing regimens in critically ill patients with susceptible life-threatening infections. J Antimicrob Chemother. 2018;73(12):3413-22. https ://doi.org/10.1093/jac/dky370.

6. Jacobs A, Taccone FS, Roberts JA, Jacobs F, Cotton F, Wolff $\mathrm{F}$, et al. $\beta$-Lactam dosage regimens in septic patients with augmented renal clearance. Antimicrob Agents Chemother. 2018;62(9):e02534-e2617. https://doi.org/10.1128/AAC.02534 $-17$.

7. Onufrak NJ, Forrest A, Gonzalez D. Pharmacokinetic and pharmacodynamic principles of anti-infective dosing. Clin Ther. 2016;38(9):1930-47. https://doi.org/10.1016/j.clint hera.2016.06.015.

8. Shaw AR, Chaijamorn W, Mueller BA. We underdose antibiotics in patients on CRRT. Semin Dial. 2016;29(4):278-80. https://doi. org/10.1111/sdi.12496.

9. Sinnollareddy MJ, Roberts MS, Lipman J, Roberts JA. Betalactam pharmacokinetics and pharmacodynamics in critically ill patients and strategies for dose optimization: a structured review. Clin Exp Pharmacol Physiol. 2012;39(6):489-96. https://doi.org /10.1111/j.1440-1681.2012.05715.x.

10. Valtonen M, Tiula E, Backman JT, Neuvonen PJ. Elimination of meropenem during continuous veno-venous haemofiltration and haemodiafiltration in patients with acute renal failure. J Antimicrob Chemother. 2000;45(5):701-4.

11. Roberts DM, Roberts JA, Roberts MS, Liu X, Nair P, Cole L, et al. Variability of antibiotic concentrations in critically ill patients receiving continuous renal replacement therapy. Crit Care Med. 2012;40(5):1523-8. https://doi.org/10.1097/CCM.0b013e3182 $41 \mathrm{e} 553$.

12. Wong G, Sime FB, Lipman J, Roberts JA. How do we use therapeutic drug monitoring to improve outcomes from severe infections in critically ill patients? BMC Infect Dis. 2014;14:288. https ://doi.org/10.1186/1471-2334-14-288.

13. Schilder L, Nurmohamed SA, Bosch FH, Purmer IM, den Boer SS, Kleppe CG, et al. Citrate anticoagulation versus systemic heparinisation in continuous venovenous hemofiltration in critically ill patients with acute kidney injury: a multi-center randomized clinical trial. Crit Care. 2014;18(4):472. https://doi. org/10.1186/s13054-014-0472-6.

14. Dellinger RP, Levy MM, Rhodes A, Annane D, Gerlach H, Opal SM, Surviving Sepsis Campaign Guidelines Committee including the Pediatric Subgroup, et al. Surviving sepsis campaign: international guidelines for management of severe sepsis and septic shock: 2012. Crit Care Med. 2013;41(2):580-637. https ://doi.org/10.1097/CCM.0b013e31827e83af.

15. Kellum JA, Lameire N, Aspelin P, Barsoum RS, Burdmann EA, Goldstein SL, Kidney Disease: Improving Global Outcomes (KDIGO) Acute Kidney Injury Work Group, et al. KDIGO clinical practice guideline for acute kidney injury. Kidney Int Suppl (2011). 2012;2(1):1-138. https://doi.org/10.1038/kisup.2012.1.

16. Huang L, Haagensen J, Verotta D, Lizak P, Aweeka F, Yang K. Determination of meropenem in bacterial media by LC-MS/MS. J Chromatogr B Analyt Technol Biomed Life Sci. 2014;961:716. https://doi.org/10.1016/j.jchromb.2014.05.002.

17. Kameda K, Ikawa K, Ikeda K, Morikawa N, Nakashima A, Ohge H, Sueda T. HPLC method for measuring meropenem and biapenem concentrations in human peritoneal fluid and bile: application to comparative pharmacokinetic investigations. J Chromatogr Sci. 2010;48(5):406-11.

18. Ulldemolins M, Vaquer S, Llauradó-Serra M, Pontes C, Calvo G, Soy D, Martín-Loeches I. Beta-lactam dosing in critically ill patients with septic shock and continuous renal replacement therapy. Crit Care. 2014;18(3):227. https://doi.org/10.1186/ cc13938.

19. Economou CJP, Wong G, McWhinney B, Ungerer JPJ, Lipman J, Roberts JA. Impact of $\beta$-lactam antibiotic therapeutic drug monitoring on dose adjustments in critically ill patients undergoing continuous renal replacement therapy. Int J Antimicrob Agents. 2017;49(5):589-94. https://doi.org/10.1016/j.ijantimica g.2017.01.009.

20. Jaruratanasirikul S, Thengyai S, Wongpoowarak W, Wattanavijitkul T, Tangkitwanitjaroen K, Sukarnjanaset M, et al. Population pharmacokinetics and Monte Carlo dosing simulations of meropenem during the early phase of severe sepsis and septic shock in critically ill patients in intensive care units. Antimicrob Agents Chemother. 2015;59(6):2995-3001. https://doi. org/10.1128/AAC.04166-14.

21. Dhaese SAM, Farkas A, Colin P, Lipman J, Stove V, Verstraete AG, et al. Population pharmacokinetics and evaluation of the predictive performance of pharmacokinetic models in critically ill patients receiving continuous infusion meropenem: a comparison of eight pharmacokinetic models. J Antimicrob Chemother. 2019;74(2):432-41. https://doi.org/10.1093/jac/dky434.

22. Jamal JA, Mat-Nor MB, Mohamad-Nor FS, Udy AA, Wallis SC, Lipman J, Roberts JA. Pharmacokinetics of meropenem in critically ill patients receiving continuous venovenous haemofiltration: a randomised controlled trial of continuous infusion versus intermittent bolus administration. Int J Antimicrob 
Agents. 2015;45(1):41-5. https://doi.org/10.1016/j.ijantimica g.2014.09.009.

23. Vardakas KZ, Voulgaris GL, Maliaros A, Samonis G, Falagas ME. Prolonged versus short-term intravenous infusion of antipseudomonal $\beta$-lactams for patients with sepsis: a systematic review and meta-analysis of randomised trials. Lancet Infect Dis. 2018;18(1):108-20. https://doi.org/10.1016/S1473 -3099(17)30615-1.

24. Tamatsukuri T, Ohbayashi M, Kohyama N, Kobayashi Y, Yamamoto T, Fukuda K, et al. The exploration of population pharmacokinetic model for meropenem in augmented renal clearance and investigation of optimum setting of dose. J Infect Chemother. 2018;24(10):834-40. https://doi.org/10.1016/j. jiac.2018.07.007.
25. Jamal JA, Mueller BA, Choi GY, Lipman J, Roberts JA. How can we ensure effective antibiotic dosing in critically ill patients receiving different types of renal replacement therapy? Diagn Microbiol Infect Dis. 2015;82(1):92-103. https://doi. org/10.1016/j.diagmicrobio.2015.01.013.

Publisher's Note Springer Nature remains neutral with regard to jurisdictional claims in published maps and institutional affiliations. 